\title{
ANALISIS TEGANGAN TEMBUS MINYAK TRANSFORMATOR DI PT. PLN(PERSERO) BOGOR
}

\author{
Christine Widyastuti ${ }^{1 *}$, Rakai Alvin Wisnuaji ${ }^{2}$ \\ 1,2 Jurusan Teknik Elektro, Sekolah Tinggi Teknik PLN \\ *Corresponding Author, email:christinewidyastuti@gmail.com
}

\begin{abstract}
Abstrak-PT.PLN (Persero) adalah penyedia listrik yang ada di Indonesia. Dalam penyaluran daya listrik, tidak seluruhnya dapat disalurkan kepada konsumen, karena akan hilang dalam bentuk rugi-rugi energi. Dengan melakukan pengujian tegangan tembus pada minyak transformator diharapkan menjadi bahan acuan untuk menjaga kinerja atau umur transformator, sehingga penyaluran energi listrik ke konsumen dapat terjaga keberlangsungannya. Pengujian dengan menggunakan Alat uji Breakdown Voltage merek Megger OTS80PB ini akan menunjukkan besar nilai tegangan tembus pada minyak transformator dengan pembebanan yang berbeda-beda.Karena semakin besar pembebanan transformator maka akan berpengaruh pada tingkat isolasi transformatornya ( minyak transforamtor). Kelayakan minyak transformator dilihat dari hasil pengujian tegangan tembus dan kadar airnya sebagai hasil simulasi kelayakan berdasarkan standar internasional untuk meningkatkan kehandalan dan dalam perawatan transformator daya dalam melayani penyaluran tenaga listrik kepada konsumen. Dengan nilai tegangan tembus yang semakin besar menunjukkan bahwa minyak transformator tersebut masih layak pakai dipergunakan. Sesuai standar uji PLN (SPLN) 49-1/1982 suatu minyak transformator sebagai bahan isolasinya harus memiliki tegangan tembus minimal 30kV/2,5mm. Dalam penelitian ini hasil pengujian dari transformator 1, transformator 2 dan transformator 3 memiliki tegangan tembus masing-masing adalah 49,4kV/2,5mm, 44,3 kV/2,5mm, 41,1 kV/2,5mm. Dari hasil tersebut dapat di katakan bahwa nilai tegangan tembus dari minyak transformator masih di atas minimal standar tegangan tembusnya sehingga masih dapat dipergunakan sebagai isolasi pada transformator.
\end{abstract}

Kata kunci : Minyak Transformator, Tegangan Tembus, Breakdown Voltage Tester Merk Megger Seri Ots80pb

Abstract - PT.PLN (Persero) is an electricity provider in Indonesia. In the distribution of electric power, not all of it can be distributed to consumers, because it will be lost in the form of energy losses. By testing the breakdown voltage on transformer oil is expected to be a reference material to maintain the performance or life of the transformer, so that the distribution of electrical energy to consumers can be maintained. Tests using the Megger OTS80PB Breakdown Voltage Test tool will show a large breakdown voltage value on the transformer oil with different loading. Because the greater the loading of the transformer, it will affect the level of isolation of the transformer (transforamtor oil). The feasibility of transformer oil can be seen from the results of testing the breakdown voltage and water content as a result of the feasibility simulation based on international standards to improve the reliability and maintenance of power transformers in serving the distribution of electricity to consumers. With a greater breakdown voltage value indicates that the transformer oil is still suitable for use. According to the PLN test standard (SPLN) 49-1 / 1982 a transformer oil as an insulating material must have a breakdown voltage of at least $30 \mathrm{kV} / 2.5 \mathrm{~mm}$. In this study the test results of transformer 1, transformer 2 and transformer 3 have a breakdown voltage of $49.4 \mathrm{kV} / 2.5 \mathrm{~mm}, 44.3 \mathrm{kV} / 2.5 \mathrm{~mm}, 41.1 \mathrm{kV} / 2.5 \mathrm{~mm}$ respectively. From these results the breakdown voltage value of the transformer oil is still above the minimum breakdown voltage standard so that it can still be used as insulation on the transformer.

Keywords: Transformer Oil, Breakdown Voltage, Breakdown Voltage Tester Brand Megger Ots80pb Series

(C) 2019 Elektron Jurnal Ilmiah

\section{PENDAHULUAN}

Transformator adalah salah satu jenis peralatan listrik yang diperlukan dalam pengyaluran tenaga listrik. Transformator (step up) pada unit pembangkit berfungsi untuk menaikan tegangan yang dihasilkan oleh generator yang kemudian disalurkan tenga llistrik maka sampailah tenga listrik ke gardu induk untuk diturunkan tegangannya melalui transformator penurung tegangan (step down) menjadi tegangan menengah atau juga disebut tegangan primer. Sebagian besar dari transformator tenaga memiliki kumparan yang intinya direndam dalam minyak transformator. Terutama pada tranformatortransformator tenaga yang kapasitas besar.

Untuk menjaga kontinunitas operasi transformator, maka pada transformator dilengkapi minyak. Minyak transformator merupakan salah satu bahan isolasi cair yang dipergunakan sebagai isolasi dan pendingin pada transformator. Sebagai bahan isolasi minyak harus memiliki kemampuan untuk menahan tegangan tembus, sedangkan sebagai pendingin minyak transformator harus mampu meredam panas yang ditimbulkan, sehingga dengan kedua kemampuan ini maka minyak diharapkan akan mampu melindungi transformator dari gangguan. Oleh karena itu agar sistem tenaga listrik dapat 
berjalan dengan baik dan handal maka keberadaan transformator harus dijaga dari gangguan khususnya yang diakibatkan oleh minyak isolasi. Karena minyak transformator mempunyai sifat sebagai media pemisah panas (disikulasi) dan juga berfungsi sebagai isolasi (memiliki daya tegangan tembus tinggi) sehingga sebagai media pendingin dan isolasi. Salah satu faktor yang menyebabkan menurunnya mutu dan ketersediaan pelayanan daya listrik adalah gangguan terhadap minyak transformator, yaitu penyebabnya bisa dari beban transformator yang

\section{METODE}

\section{A. Analisa Kebutuhan}

Untuk mendapatkan perumusan, analisa dan penyelesaian masalah maka dibutuhkan pengumpulan data dan fakta yang lengkap, relevan dan objektif serta dapat dipercaya kebenarannya. Maka dari itu, proses pengumpulan data, lalu menganalisa studi kasus dan menyusun laporan penelitian dengan menggunakan metode studi literatur, studi Pustaka dan konsultasi.

\section{B. Perancangan Penelitian}

Dalam penelitian ini dilakukan pengujian tegangan tembus dengan menggunakan alat Breakdown voltage merek Megger seri OTS8OPB dengan standar IEC156 yang temperature suhunya telah

\section{HASIL DAN PEMBAHASAN}

\section{A. Transformator Daya}

Transformator adalah alat yang digunakan untuk memindahkan energi listrik arus bolak-balik dari suatu rangkaian yang lain dengan prinsip kopel atau suatu gandengan magnet berdasarkan prinsip induksi electromagnet. Sebagian besar kumparankumparan dan inti transformator tenaga direndam dalam minyak transformator, terutama transformator-transformator tenaga yang berkapasitas besar, karena minyak transformator mempunyai sifat sebagai isolasi dan media pemindah, sehingga minyak transformator tersebut sebagai media pendingin dan isolasi. Sebagai bahan isolasi minyak transformator memiliki beberapa kekentalan, hal ini sebagaimana dijelaskan dalam SPLN (49-1:1980). Adapun persyaratan yang harus dipenuhi oleh minyak transformator salah satunya adalah tegangan tembus dan kandungan air di dalam minyak tersebut harus sesuai dengan standar yang digunakan. Tegangan yang dihasilkan dapat lebih besar (step-up) atau lebih kecil (step-down) dengan frekuensi yang sama. Dengan adanya pembebanan pada transformator maka akan berpengaruh pada kondisi isolasi minyak transformatornya. tinggi, lama pemakaian dari transformator dan adanya kadar air yang tinggi pada transformator. Semakin kecilnya tegangan tembus pada minyak transformator membuktikan bahwa minyak transformator mengalami gangguan dan harus di treatment atau diganti minyak tersebut.

Oleh karena itu, pada penelitian ini akan dibahas tegangan tembus minyak transformator agar menyesuaikan dengan standar, yaitu standar SPLN No.49/1982/Unit KV/2,5mm dan dengan metode IEC 156 yaitu minimal 40KV/2,5mm.

ditetapkan dari alat yang digunakan dari jarak elektroda yang telah ditetapkan oleh alat pengujian . Data data yang digunakan dalam penelitian ini terdiri dari dua yaitu data primer dan data sekunder. Uraiannya adalah sebagai berikut:

a. Data Primer

Data primer adalah data yang diperoleh di lapangan dari hasil pengukuran, perhitungan dan pengamatan langsung pengujian tegangan tembus pada minyak transformator yang dijadikan sebagai pokok pembahasan pada proyek akhir ini.

b. Data Sekunder

Data Sekunder adalah data yang bersumber dari buku referensi dan jurnal yang relevan dengan pembahasan penelitian ataupun terdapat pada lapangan. Pemilihan jenis metode ini didasarkan pada data penyusunan proyek akhir. Karena dalam data sekunder ini dapat dihasilkan berupa data yang sangat memumpunin yang valid.

Di dalam penelitian ini akan di ambil beberapa sampel minyak trafo dari PT PLN (Persero) Bogor. Sample yang telah di ambil diujikan di Laboratorium Kimia STT - PLN, untuk diujikan nilai tegangan tembus dan kadar airnya dari sample yang sudah digunakan bertahun-tahun. Setelah itu baru kita bandingkan dari masing-masing sampel tersebut manakah yang masih baik untuk digunakan dan mana yang sebaiknya diganti.

\section{B. Breakdown Voltage Test}

Tes Tegangan tembus (Breakdown Voltage Test) adalah salah satu uji predictive maintance yang dilakukan pada minyak isolasi (minyak). Tujuan uji ini adalah untuk mengetahui kemampuan isolasi minyak terhadap tegangan yang diberikan jika nilai Tegangan tembus tinggi bisa disimpulkan bahwa minyak dalam kondisi yang masih baik dan begitu juga sebaliknya. Breakdown Voltage Merk Megger seri OTS80PB didesain lengkap memenuhi standard pengukuran internasional. Alat ini dilengkapi dengan bejana minyak yang sangat mudah untuk dibersihkan Elektroda dimasukan mendatar ke dalam bejana pengukur, yaitu mencegah medan listrik yang 
disebabkan turbulensi dan korona. Ini juga memungkinkan penentuan sample minyak dengan jarak dari elektroda dapat ditentukan dengan puller 2,5

Tabel 1 . Data Spesifikasi Transformator

\begin{tabular}{cccccc}
\hline Gardu & Penyulang & KVA & Merk & $\begin{array}{c}\text { Daya } \\
\text { Terukur } \\
\text { (KVA) }\end{array}$ & $\begin{array}{c}\% \\
\text { Beban } \\
\text { Trafo }\end{array}$ \\
\hline Kle & ATOM & 630 & UNINDO & 610,1 & 96,84 \\
\hline Azrt & ATOM & 630 & UNINDO & 63,5 & 10,08 \\
\hline KIJ & BELIUNG & 630 & B\&D & 343,1 & 54,46
\end{tabular}

Tabel 2. Percobaan Tegangan Tembus

\begin{tabular}{cccc}
\hline Percobaan & $\begin{array}{c}\text { Sampel } \\
\text { Minyak } \\
(1)\end{array}$ & $\begin{array}{c}\text { Sampel } \\
\text { Minyak } \\
2)\end{array}$ & $\begin{array}{c}\text { Sampel } \\
\text { Minyak } \\
(3)\end{array}$ \\
\hline 1 & $52,5 \mathrm{kV}$ & $40,8 \mathrm{kV}$ & $45,8 \mathrm{kV}$ \\
\hline 2 & $50,4 \mathrm{kV}$ & $51,8 \mathrm{kV}$ & $37,5 \mathrm{kV}$ \\
\hline 3 & $43,4 \mathrm{kV}$ & $52,1 \mathrm{kV}$ & $52,7 \mathrm{kV}$ \\
\hline 4 & $29,5 \mathrm{kV}$ & $56,1 \mathrm{kV}$ & $43,6 \mathrm{kV}$ \\
\hline 5 & $38,8 \mathrm{kV}$ & $49,3 \mathrm{kV}$ & $36 \mathrm{kV}$ \\
\hline 6 & $32,4 \mathrm{kV}$ & $46,5 \mathrm{kV}$ & $50,3 \mathrm{kV}$ \\
\hline Rata-rata & $41,1 \mathrm{kV}$ & $49,4 \mathrm{kV}$ & $44,3 \mathrm{kV}$ \\
\hline
\end{tabular}

Dari tabel diatas didapatkan transformator 1 dengan pembebanan $96,84 \%$ dengan tegangan tembus rata-rata $41,1 \mathrm{kV}$, transformator 2 dengan pembebanan $10,08 \%$ dengan tegangan tembus rata-rata $49,4 \mathrm{kV}$, dan transformator 3 dengan pembebanan 54,46\% Perhitungan rata-rata tegangan tembus minyak 1 adalah :

$V b($ rata - rata $)=\frac{52,5+50,4+43,4+29,5+38,8,+32,4}{6}$

$$
=41,1 \mathrm{kV} / 2,5 \mathrm{~mm}
$$

Perhitungan rata-rata tegangan tembus minyak 2 dimana :

$$
\begin{aligned}
V b(\text { rata }- \text { rata }) & =\frac{40,8+51,8+52,1+56,1+49,3+46,5}{6} \\
& =\mathbf{4 9 , 4} \mathbf{~} \mathbf{V} / \mathbf{2}, \mathbf{5} \mathbf{m m}
\end{aligned}
$$

Perhitungan rata-rata tegangan tembus minyak 3 adalah $\mathrm{mm}$, sebagai gap/jarak dan tanpa memasang alat ukur melalui perpanduan meter yang disesuaikan.

Perhitungan kekuatan dielektrik minyak menggunakan rumus berikut :

$V b($ rata - rata $)=$

$\frac{\sum_{i=1}^{n} U i}{N}$

$$
\begin{aligned}
& \text { Dimana : } \\
& \mathrm{Ui}=\text { Nilai tegangan tembus }(\mathrm{kV}) \\
& \mathrm{N}=\text { Jumlah pengujian } \\
& \mathrm{E}=\text { Kekuatan dielektrik }(\mathrm{kV} / \mathrm{mm}
\end{aligned}
$$

Dari perhitungan diatas pengujian $>30 \mathrm{kV} / 2,5 \mathrm{~mm}$, maka hasil tersebut menujukan bahwa minyak dalam keadaan baik dan dapat beroperasi normal. Apabila hasil dalam keadaan < $30 \mathrm{kV} / 2,5 \mathrm{~mm}$, maka hasil tersebut menunjukan bahwa minyak dalam keadaan kurang baik, sehingga perlu adanya penggantian minyak untuk mencegah terjadinya kegagalan pengujian telah sesuai dengan standart pada tabel 3 .

Tabel 3. Standart Tegangan Tembus / Dialectric Strenght, Standart IEC 156

\begin{tabular}{ccc}
\hline $\begin{array}{c}\text { Tegangan } \\
\text { Operasi } \\
(\mathbf{k V})\end{array}$ & $\begin{array}{c}\text { Jarak } \\
\text { gap } \\
(\mathbf{m m})\end{array}$ & $\begin{array}{c}\text { Nilai } \\
\text { minimum } \\
(\mathbf{k V})\end{array}$ \\
\hline Un $\leq 36$ & 2,5 & 30 \\
\hline $36<$ Un $\leq 70$ & 2,5 & 35 \\
\hline $\begin{array}{c}70<\mathrm{Un} \leq \\
170\end{array}$ & 2,5 & 40 \\
\hline Un $>170$ & 2,5 & 50 \\
\hline
\end{tabular}

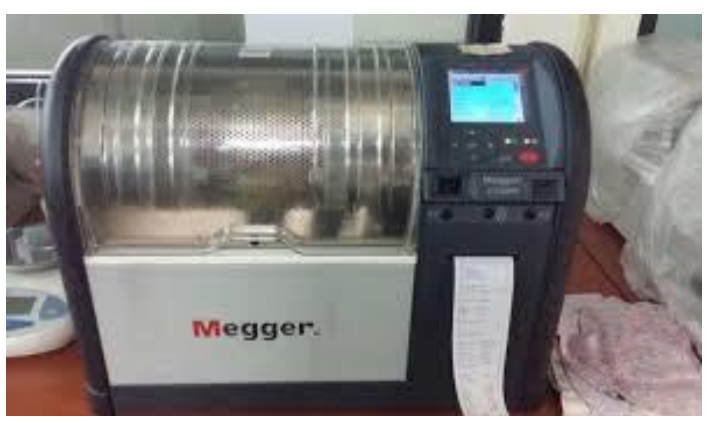

Gambar 1 Breakdown Voltage merek Megger OTS80PB 


\section{IV.KESIMPULAN}

Dengan menghitung dari rata-rata hasil pengujian dan perhitungan tegangan tembus didapati bahwa pada Sampel minyak A ( Transformator 1 ) hasil rata- rata tegangan tembus $41,1 \mathrm{kV} / 2,5 \mathrm{~mm}$, untuk sampel minyak B ( Transformator 2 ) hasil rata- rata tegangan tembus $49,4 \mathrm{kV} / 2,5 \mathrm{~mm}$ dan pada sampel C ( Transformator 3 ) hasil rata- rata tegangan tembus $41,1 \mathrm{kV} / 2,5 \mathrm{~mm}$. Dari hasil tersebut dapat dikatakan bahwa ketiga sampel minyak transformator yang terpakai di masing-masing gardu distribusi tersebut masih sesuai dengan (SPLN) 491/1982 yang besarnya > $30 \mathrm{kV}$ sehingga masih layak digunakan.

\section{REFERENSI}

1. Asep Saepuloh, Dkk, Evaluasi Unjuk Kerja Trafo Berpendingin Minyak, Buletin Reaktor,Vol. III, No.2,Okt 2006:1-10

2. Christine,Widyastuti.Oktaria,Handayani.Tasdik,Dar mana. Pengaruh Kadar Air Terhadap Tegangan Tembus Minyak Transformator Distribusi, Jurnal : Energi dan Kelistrikan, Volume 10 No.2 ( 2018 ).
3. Kadir, Abdul. "Transformator", PT. Elex Media Koputido,1989

4. Rahmawati, Sri Agustina, Monang R Manalu, Evaluasi Kandungan Air Terhadap Tegangan Tembus Pada Minyak Jarak Yang Telah Melalui Proses Transesterifikasi Sebagai Alternatif Minyak Transformator “, STTPLN:2014

5. SPLN, 49-1 Minyak Isolasi Pada Transformator, 1982.

6. Asep Saepuloh, Yayan Andriyanto.(view Oktober 2019).Pengujian Karakteristik Minyak Sebagai Media Isolasi Trafo Pada Sistem Kelistrikan Di Rsg-Gas.Buletin Pengelolaan Reaktor Nuklir. Vol. 5 No. 2, Oktober 2008: 9 - 16. http://repo-nkm.batan.go.id/5305/1/AsepS_ok.pdf

7. Badaruddin, Fery Agung Firdianto.Analisa Minyak Transformator Pada Transformator Tiga Fasa Di PT X, Jurnal Teknik Elektro,Universitas Mercu Buana,ISSN 2086-9479, Vol 7 No.2.

8. Tajudin,1998 "Analisis Kegagalan Minyak Transformator", Elektro Indonesia, Edisi 12 Maret. https://core.ac.uk/download/pdf/11724484.pdf

9. Garniwa Iwa, Fritz. S Jonathan. 2009, Analisis Pengaruh Kenaikan Temperatur Dan Umur Minyak Transformator Terhadap Degradasi Tegangan Tembus Minyak Transformator. Jurnal, Departemen Teknik Elektro, Universitas Indonesia, Depok. 